\title{
Role of bile in non-specific defence mechanisms of the gut
}

\author{
T Kalambaheti, G N Cooper, G D F Jackson
}

\begin{abstract}
The effect of depriving the intestine of bile for $\mathbf{4 8}$ hours was studied to determine any influence on various parameters of innate immunity in the gastrointestinal tract. Groups of rats were prepared by bile duct cannulation (with or without fluid replacement) or bile duct ligation. Normal and sham operated animals were used for comparing the thickness of the mucus layer and the cells contained therein, enumeration of goblet cells, and measurement of villus size. Histological examination indicated that the intestinal tissues of treated and control rats were similar. Though villus size and numbers of goblet cells were unaffected, a significant reduction occurred in the thickness of the mucus blanket in the duodenal regions of rats deprived of bile, and there were significantly lower numbers of mucus associated enterocytes and lymphocytes, suggesting a lower turnover rate of the epithelium. The balance of the bacterial populations in the caecum and intestine was altered by bile deprivation increased numbers of coliform organisms were found in both regions. The range of factors, including antibodies and other known constituents, present in bile may contribute to the maintenance of tissue integrity and influence the balance in indigenous bacterial populations in the intestine. Disturbance of the host's biliary system and concomitant effects on the microbial flora may weaken the overall processes of defence in the intestine.

(Gut 1994; 35: 1047-1052)
\end{abstract}

In recent times considerable attention has been given to the secretory adaptive immune system in mediating protection in the gastrointestinal tract. The induction and function of secretory IgA antibodies has been given high priority by those interested in exploiting immune mechanisms to control important bacterial and virus diseases of man. ${ }^{1}$ The finding that the hepatobiliary system carries immunoglobulins $^{2-4}$ raises the possibility that it may also contribute to immunity through delivery of protective antibodies to the gut fluids, 56 but its role in innate defence against microbial infection is unclear. The increased incidence of infections with organisms normally regarded as constituents of the gut bacterial ecosystem in a variety of conditions that affect the production and/or flow of bile ${ }^{78}$ might suggest that the absence of bile from intestinal fluid has disturbed, and presumably reduced, the efficacy of the natural defence mechanisms.

The present studies were undertaken in an attempt to determine whether bile has any impact on the natural intestinal defence mechanisms. The rat was chosen because it does not possess a gall bladder or cystic duct, thus making it possible to deprive the intestine of bile (but not pancreatic juices) through ligation or cannulation. The obvious approach of challenging animals treated in such a way with specific microbial infections was clearly not appropriate, however, as any increased susceptibility could easily be attributed to the trauma resulting from the surgical procedures. The alternative has been to examine the effects of bile deprivation on several physical and biological parameters believed to be involved in innate resistance. Since bile flows into the lumen of the intestine, it is reasonable to assume that its effects, if any, will be associated with resistance mechanisms expressed at or associated with the epithelial surfaces; several such factors have been investigated herein.

\section{Methods}

\section{ANIMALS}

Male Wistar rats of approximately the same age and weighing between 250 and $350 \mathrm{~g}$ were used. Groups designated as normal rats (N) were housed in plastic boxes on sawdust bedding, fed with a commercial fluorine and urea free diet (Rat and Mouse Kubes, Allied Feeds, Sydney), and given free access to water.

\section{SURGICAL METHODS}

Groups of rats were anaesthetised with ether and treated as follows:

\section{(i) Bile duct cannulation}

The method described by Lambert ${ }^{9}$ was used. Briefly, polythene tubing (internal diameter $28 \mathrm{~mm}$ and outside diameter $0.68 \mathrm{~mm}$ ) was inserted into the bile duct at a point further than $10 \mathrm{~mm}$ from its entry into the duodenum. After surgery the animals were housed in restraining cases and were given food and free access to water over that period.

(ii) Bile duct cannulation with fluid replacement The bile ducts were cannulated as described in (i). A small opening was made in the abdomen close to the point at which the duodenal papillae connects with the abdominal wall. Polythene tubing was inserted through this 
opening and then into the duodenum in the direction of the ileum and fixed with two purse string sutures of nylon silk and one of surgical cat gut. The tubing was connected to a peristaltic pump (Microperpex, LKB) which maintained a flow of sterile normal saline of $0.7 \mathrm{ml} / \mathrm{h}$ into the duodenum. This rate was chosen as it approximated to the flow of bile through the cannula. The animals were kept in restraining cages and given food and free access to water.

\section{(iii) Bile duct ligation}

The common bile ducts of each animal were ligated in two places with silk sutures; rats were kept in groups of four in plastic cages and given food and free access to water.

\section{(iv) Sham operation}

Groups of rats were anaesthetised with ether and a $25-30 \mathrm{~mm}$ incision was made through the abdominal wall. After five minutes, the incision was sutured and the animals were kept in the restraining cages used for the first two groups of rats.

Unless stated otherwise, treated rats were killed by spinal dislocation under ether anaesthesia 48 hours after surgery.

MEASUREMENT OF MUCUS GEL THICKNESS A modification of the method described by Keress et al ${ }^{10}$ was used. Briefly, 1-2 cm long sections of intestinal tissue were opened longitudinally and washed gently in saline. They were mounted on a Millipore filter with the lumenal surface uppermost and 1.0-1.5 mm sections were cut with a razor blade placed at right angles to the mucosal surface. Clear adhesive tape was placed on glass microscope slides to support the sections, which were mounted transversely and viewed

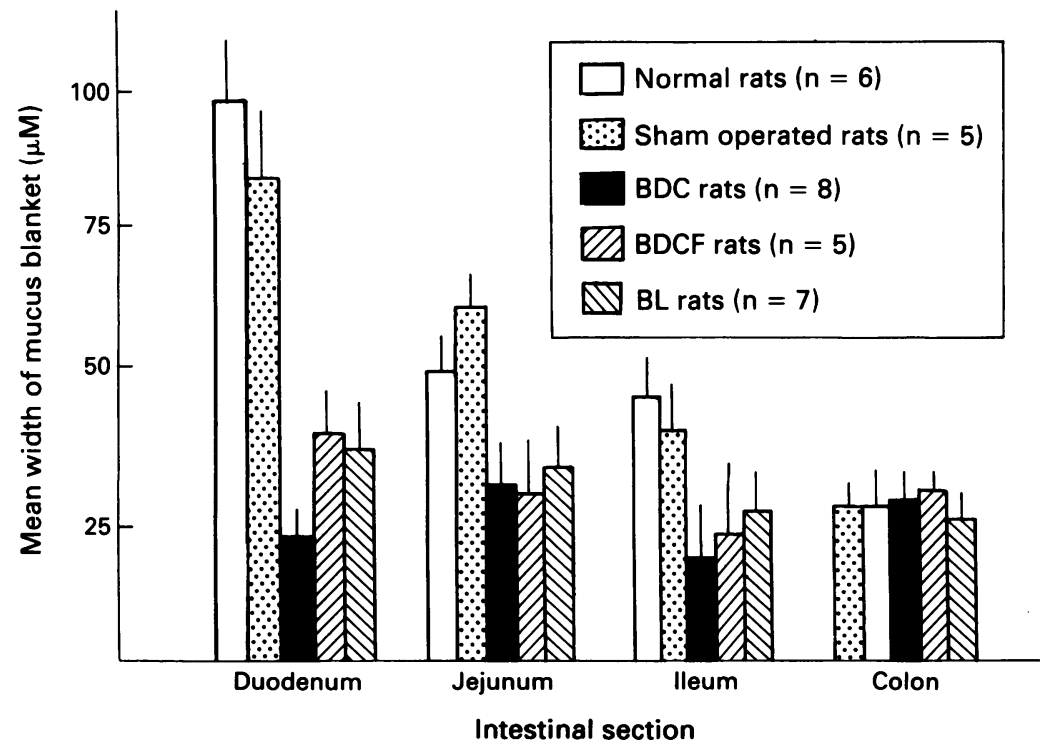

Figure 1: Effects of bile duct perturbation on width of the mucus blanket in the rat intestine: error bars indicate $S D s . B D C=$ bile duct cannulated rats; $B D C F=$ bile duct cannulated rats given saline perfusion of the intestine; $B L=$ bile duct ligated rats. Figures in parentheses indicate number of animals in each group. with an inverted microscope ( $\times 10$ magnification). The mucus gel appeared as a translucent layer above the black of the mucosa and filter paper layers. Gel thickness was measured with an eyepiece graticule calibrated against a stage micrometer. Four sections of each of the tissue regions were examined and four separate measurements were taken for each section: mean (SD) values were determined from the 16 individual measurements. Unless otherwise stated, sections from the duodenum and the jejunum were taken $2-5 \mathrm{~cm}$ and $20-25 \mathrm{~cm}$ respectively from the pylorus, ileal sections were taken 5-10 cm from the ileocaecal junction, and colonic sections were from the mid-point of the colon.

PREPARATION OF CELLS FROM INTESTINAL MUCUS

Rats were fasted for 18 hours then killed by spinal dislocation under ether anaesthesia. The small intestines were removed and divided into three equal length segments, each of which was flushed out with phosphate buffered saline (PBS-pH 7·2). They were then tied at one end with cotton, filled with $10-15 \mathrm{ml}$ of $\mathrm{N}$-acetyl-1-cysteine solution (prepared by adding $1.25 \mathrm{~g}$ to $50 \mathrm{ml}$ of PBS and adjusting to pH $7 \cdot 2$ with $5 \mathrm{~N} \mathrm{NaOH}$ ) then tied at the other end. Small intestines were incubated for five minutes at room temperature then opened to collect the fluid contents. Each segment was again flushed with PBS $(10 \mathrm{ml})$ and the washings from each segment were.combined with its fluid contents. Cells were collected after centrifugation at $100 \mathrm{~g}$ for 10 minutes. The cells were washed once in RPMI 1640 medium (CSL, Parkville, Victoria) and recovered by centrifuging as before. They were then separated by Percoll density gradient centrifugation. Ninety two volumes of Percoll (Pharmacia, Sweden) were diluted with eight volumes of $10 \times$ concentrated PBS. Different concentrations of the Percoll were then prepared by dilution in RPMI 1640 medium containing $10 \%$ fetal calf serum (CSL, Parkville, Victoria). The gradient was prepared by layering $2.5 \mathrm{ml}$ volumes of $80 \%, 35 \%, 25 \%$, and $15 \%$ Percoll in $15 \mathrm{ml}$ conical glass tubes; the cells were resuspended in $3 \mathrm{ml}$ of $7 \%$ Percoll containing $3 \mathrm{mg} / \mathrm{ml}$ dithiothreitol (Sigma, USA) and layered onto the gradient surface. They were centrifuged at $700 \mathrm{~g}$ in a Beckman JJ6R centrifuge with a $\mathrm{TH}-4$ rotor for 20 minutes at $4^{\circ} \mathrm{C}$. Cells banding over the upper three layers were predominately mononuclear and despite variations in form from a few typical epithelial cells to large numbers of vacuolated and multigranular cells (classified as enterocytes), approximately $95 \%$ viability was found when assessed by the trypan blue dye exclusion test. The numbers of cells present in each preparation were determined by counting in a Neuberg haemocytometer. Preliminary studies of stained sections of intestinal segments indicated that the mucosal surfaces were largely unaffected by this treatment with $\mathrm{N}$-acetyl-1-cysteine. 


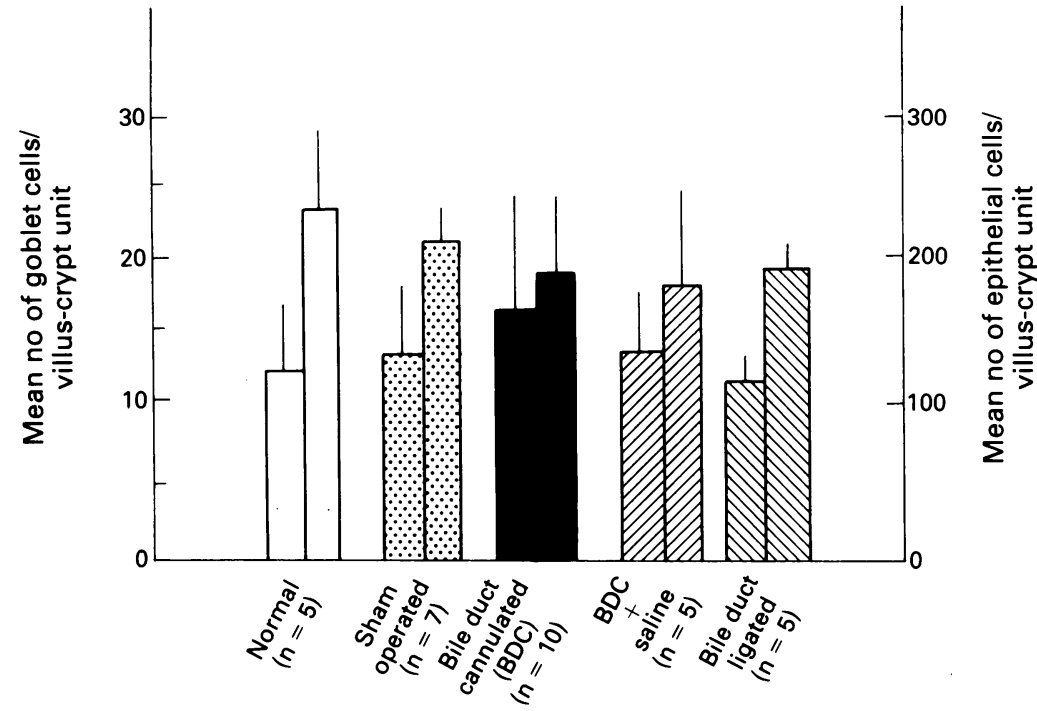

Figure 2: Goblet cells (left hand columns) and villus size (right hand columns) in the duodenum of normal and bile duct perturbed rats; error bars indicate SDs.

DETERMINATION OF VILLUS SIZE AND NUMBERS OF GOBLET CELLS

Sections of intestine were prepared and stained by haematoxylin and eosin. The villus size was estimated by the method of Altmann and Leblond, ${ }^{11}$ examining 10 villi per section, and was expressed as the mean (SD) number of cells per villus-crypt unit. The numbers of unstained goblet cells in the 10 villus sections were determined and expressed as the mean (SD) number per villus-crypt unit.

ENUMERATION OF BACTERIAL POPULATIONS Duodenal, jejunal, ileal, caecal, and colonic sections weighing $0.5 \mathrm{~g}$ were placed in $5 \mathrm{ml}$ volumes of nutrient broth containing glass beads then stirred vigorously in a Vortex mixer. The method of Schaedler et al ${ }^{12}$ was used to estimate numbers of organisms present in the sections. Standard loopfuls of the homogenates (and dilutions of them) were plated on brain heart infusion agar (BHIA) and

TABLE I Recovery of cells from mucus eluates prepared from sections of rat small intestine after five minutes' incubation in $2 \cdot 5 \%(w / v)$ of $N$-acetyl-l-cysteine

\begin{tabular}{lclll}
\hline \multirow{2}{*}{$\begin{array}{l}\text { Intestinal } \\
\text { section }\end{array}$} & $\begin{array}{l}\text { Mean }(S D) \text { no } \\
\text { of cells } \times 10^{4} \\
\text { per section }\end{array}$ & \multicolumn{4}{l}{ Mean (SD) cells with morphological characteristics of } \\
\cline { 3 - 6 } \cline { 4 - 6 } & Epithelial cells (\%) & $G$ and V cells $\ddagger(\%)$ & Lymphocytes (\%) \\
\hline Duodenum & $1500(544)$ & $12(3)$ & $72(4)$ & $16(2)$ \\
Jejunum & $349(576)$ & $9(2)$ & $72(8)$ & $19(4)$ \\
Ileum & $10(19)$ & $34(10)$ & $61(3)$ & $5(2)$
\end{tabular}

^Mean (SD) determined from seven rats; $\nmid$ includes $10 \mathrm{~cm}$ of jejunum; $\ddagger$ multigranulated $(\mathrm{G})$ and vacuolated $(\mathrm{V})$ cells.

TABLE II Effect of bile duct cannulation on numbers of mononuclear cells in mucus eluates prepared from section of rat small intestine treated with $2 \cdot 5 \%(w / v) N$-acetyl-l-cysteine

\begin{tabular}{|c|c|c|c|c|}
\hline \multirow{3}{*}{$\begin{array}{l}\text { Intestinal } \\
\text { section }\end{array}$} & \multicolumn{4}{|c|}{ Mean $(S D)$ no of cells $\left(\times 10^{-4}\right)$ recovered from rats treated by: } \\
\hline & \multicolumn{2}{|l|}{ Sham operation ${ }^{\star}$} & \multicolumn{2}{|c|}{ Bile duct cannulation $\dagger$} \\
\hline & Epithelial cells $\ddagger$ & Lymphocytes & Epithelial cells $\ddagger$ & Lymphocytes \\
\hline $\begin{array}{l}\text { Duodenum } \\
\text { Jejunum } \\
\text { Ileum }\end{array}$ & $\begin{array}{c}1161(531) \\
43(31) \\
4(2)\end{array}$ & $\begin{array}{c}447(352) \\
43(26) \\
0\end{array}$ & $\begin{array}{l}57(48) \\
53(44) \\
41(53)\end{array}$ & $\begin{array}{l}27(31) \\
33(36) \\
23(32)\end{array}$ \\
\hline
\end{tabular}

^Mean (SD) determined from three rats; animals examined two days after operation; †mean (SD) determined from 10 rats; animals examined two days after operation; fincludes elongated epithelial cells, multigranulated, and vacuolated cells.
McConkey agar (MCA) media. Numbers of aerobic organisms were determined from the BHIA plates after 48 hours' incubation at $37^{\circ} \mathrm{C}$; similar plates incubated anaerobically for the same time and at the same temperature provided an estimate of the anaerobic populations. Coliform numbers were determined from MCA plates incubated aerobically at $37^{\circ} \mathrm{C}$ at the same time. The method of Phillips et al $^{13}$ was used to estimate populations of morphologically different organisms in intestinal contents. Material from the caecum and colon $(0.5 \mathrm{~g}$ amounts) were suspended in $5 \mathrm{ml}$ of saline and homogenised in a Vortex mixer. Films were prepared on slides then heat fixed and stained by Gram. Subjective errors likely to arise from microscopic assessment of numbers of different types of organisms were eliminated by using a rigorous blind system of counting in which all slides were assigned numbers then examined randomly over a period of days. Percentages of organisms were classified into three groups as follows: (i) large fusiforms and thin tapered rods; (ii) curved and spiral shapes; and (iii) other categories - that is, rods and cocci) were determined after the slides were decoded.

\section{Results}

The thickness of the mucus blanket in the duodenal, jejunal, ileal, and colonic regions of the intestines of normal, sham operated, and 'bile duct modified' rats is compared in Figure 1. In both normal and sham operated rats, it is greatest in the duodenum (circa 80-100 $\mu \mathrm{m}$ ) and least in the colon (circa $30 \mu \mathrm{m})$. When bile was excluded from the intestine by cannulation, the mucus thickness was reduced by around $80 \%$ in the duodenum and by $50 \%$ in the jejunum and ileum but was unaffected in the colon. When tested by one way analysis of variance (ANOVA) the only significant reduction in mucus thickness was found in the duodenum $(p<0.05)$. When saline infusion was used to replace the $15-20 \mathrm{ml}$ of bile fluid entering the duodenum daily, mucus thickness in this region was still around $50 \%$ less than that found in normal and sham operated animals. This was also the case in rats in which systemic dehydration through loss of bile was prevented by bile duct ligation. In both these cases, reductions in the thickness of the duodenal blanket were statistically significant when tested by ANOVA $(\mathrm{p}<0.05)$ in comparison with normal and sham operated animals. No significant changes in mucus thickness were found in other regions of the intestine. Figure 2 indicates that the changes in the duodenum after the interruption of bile flow were not accompanied by reductions in villus size or in the numbers of goblet cells lining the duodenal villi.

Previous studies have shown that the intestine's mucus blanket can be eluted by short term (3-5 minutes) treatment with the mucolytic agent $\mathrm{N}$-acetyl-1-cysteine without significant damage to the epithelial surface itself. ${ }^{14}$ Table I indicates that mucus eluates obtained by this treatment contain cells 


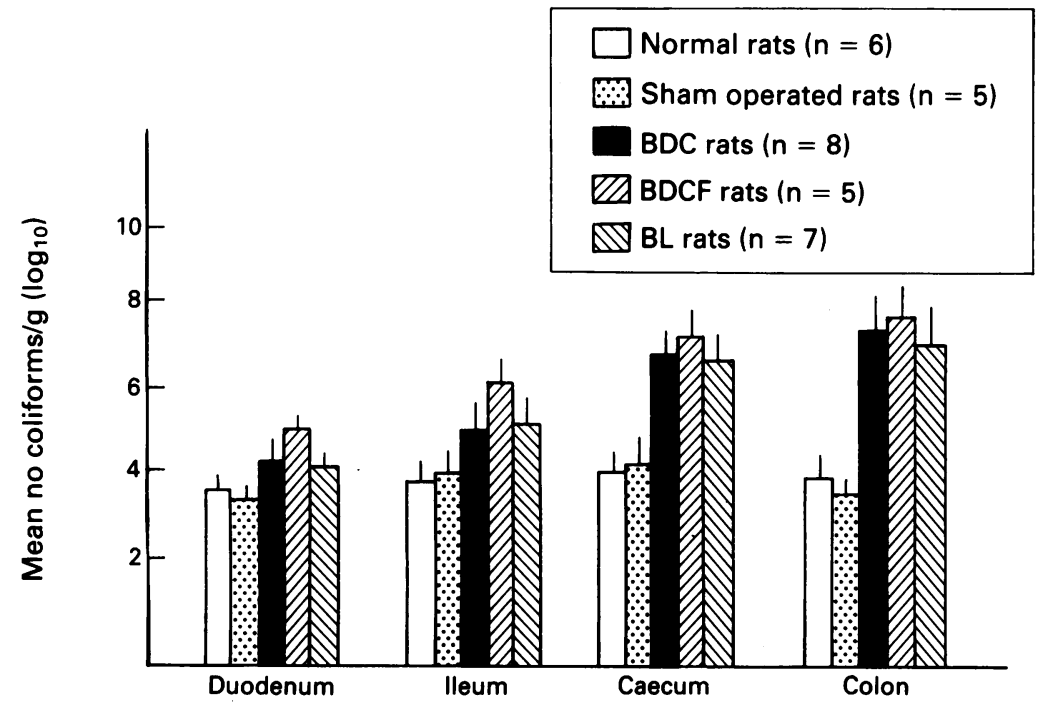

Figure 3: Numbers of coliform organisms in the intestines of rats after perturbation of the bile duct; error bars indicate $S D s . B D C=$ bile duct cannulated rats; $B D C F=$ bile duct cannulated rats given saline perfusion of the intestine; $B L=$ bile duct ligated rats.

with varying morphological characteristics; moreover, their numbers differ in eluates prepared from different regions of the small intestine. In sections taken from normal rats, most mucus associated cells occurred in eluates from the duodenal-jejunal region while the fewest were found in ileal eluates. In all instances, granular and vacuolated cells predominated (in excess of $60 \%$ of the total); the remaining cells in each preparation were readily identified as lymphocytes and epithelial cells.

Mucus associated cells obtained from sections of small intestine prepared from sham operated and bile duct cannulated rats are compared in Table II. Exclusion of bile from the small intestine led to reductions of 10-20 fold in cell numbers present in mucus eluates prepared from the duodenal-jejunal region, whereas the numbers of cells recovered from more distal intestinal regions of the two groups of animals were not significantly different.

Microbial populations of the duodenum, ileum, caecum, and colon of normal, sham operated, bile duct cannulated (some receiving intraduodenal saline infusion) and bile duct ligated rats were assessed by viable counting procedures 48 hours after surgery. In the case of the anaerobic populations, numbers were least in the duodenal and jejunal sregions (circa $10^{8}$ per $\mathrm{g}$ tissue) and greatest in the

TABLE III Effect of bile duct cannulation on rat caecal flora

\begin{tabular}{|c|c|c|c|c|c|}
\hline \multirow[b]{2}{*}{ Rate treatment } & \multirow[b]{2}{*}{ No of rats } & \multicolumn{3}{|c|}{ Percentage of population classified ${ }^{\star}$ as } & \multirow{2}{*}{$\begin{array}{l}\text { Mean (SD) } \\
\text { no of coliforms } \\
\left(\log _{10}\right)\end{array}$} \\
\hline & & Fusiformst & Curved rods $\ddagger$ & Others $\$$ & \\
\hline $\begin{array}{l}\text { None } \\
\text { Sham operation } \\
\text { BDC-1 }{ }^{\star \star} \\
\text { BDC-2 }{ }^{\star \star} \\
\text { BDC (infused) }+\dagger\end{array}$ & $\begin{array}{l}3 \\
3 \\
3 \\
3 \\
3\end{array}$ & $\begin{array}{r}53 \\
24 \\
25 \\
1 \\
14\end{array}$ & $\begin{array}{l}4 \\
2 \\
6 \\
0 \\
0\end{array}$ & $\begin{array}{l}43 \\
74 \\
69 \\
99 \\
86\end{array}$ & $\begin{array}{l}3 \cdot 8(0 \cdot 4) \\
4 \cdot 3(2 \cdot 0) \\
5 \cdot 4(1 \cdot 5) \\
8 \cdot 7(0.9) \neq \neq \\
7 \cdot 9(1 \cdot 1) \neq \ddagger\end{array}$ \\
\hline
\end{tabular}

^Determined by microscopic examination of slides prepared from caecal contents of rats two days after surgery; $\dagger$ includes Gram negative organisms with fusiform or tapered rod morphology; $¥$ includes Gram negative curved rods and spiral shaped organisms; $§$ includes Gram negative and Gram positive rods, cocci and cocco-bacilli; ${ }^{\star}$ bile duct cannulated animals; sub-groups based on presence of normal or high numbers of coliforms determined by viable counting of caecal contents; $+t$ bile duct cannulated rats infused intraintestinally with saline; \# statistically different from numbers found in normal and sham operated groups $(p<0.05$ by the ANOVA test). caecum and colon (circa $10^{9-10}$ per $\mathrm{g}$ tissue). Numbers of aerobic organisms were usually fewer (ranging from around $10^{6}$ per $g$ in the duodenum to $10^{8-9}$ per $\mathrm{g}$ in the colon). In no instance were the numbers of these groups of organisms affected by bile duct cannulation or ligation. In contrast, as shown in Figure 3, increases in the numbers of organisms capable of growing on MCA (primarily coliforms) were found in most intestinal regions of rats which had undergone bile duct modification; the most significant and consistent changes were found in the caecum and colon.

Previous studies in mice ${ }^{13}$ have shown that increases of coliforms in the intestine were associated with quantitative and qualitative changes in the microbial flora of the caecum. The possibility that similar inter-relationships existed in bile deprived intestines of the rat was therefore investigated using an objective qualitative microscopic assessment method described by those authors. At the same time, coliform numbers in the caeca of the individual rats were determined by viable counts. The results are summarised in Table III. For simplicity, organisms present in the caecal contents were assigned to three distinct morphological groups. The first group clearly forms a large percentage of the caecal population in normal and sham operated animals but their numbers were affected when bile flow to the intestine was prevented over a two day period. For reasons which are not immediately obvious, changes in the populations were observed in only half of the bile duct cannulated animals. Importantly, however, in one of those subgroups, the percentage of fusiforms and tapered rods was greatly reduced while coliform numbers greatly exceeded those in the two control groups; in the other subgroup changes in neither of the two morphological groups were found. Findings in the group of rats which were bile duct cannulated and received intraintestinal saline infusion for two days also suggested that significant increases of coliform numbers were associated with decreases in the fusiform and tapered rod populations of the caecum.

\section{Discussion}

Mucosal surfaces, which are at continuous risk from environmental agents, are equipped with a full array of innate and adaptive immune processes in order to maintain tissue integrity. The magnitude of the surface area of the gastrointestinal tract and, under normal circumstances, the presence of ingested material together with the indigenous microbiota demand a particularly potent defence system, yet one which has great subtlety so that the prime function of food absorption is not compromised. Our interest in the hepatobiliary transfer of immunoglobulins and their contribution to immunity in the gut has led to this initial study into the possibility that biliary factors influence other aspects of natural host defence. In general terms, the results show that after a short period of bile deprivation, significant changes occur in 
certain physical and biological properties of the intestine without any apparent changes to tissue structure or the cellular distribution within the epithelium.

Mucus provides a thick gel coating for the intestinal epithelium and is a natural physical barrier to potential pathogenic bacteria; only adaptable spiral organisms are likely to be present in it. $^{15}$ The results reported here suggest that while there is a requirement for adequate hydration, the thickness of the mucus coat in the duodenal region is partly dependent upon the normal flow of bile. This reduction could enhance susceptibility to invading organisms by permitting readier access to the epithelial surface across this natural barrier. There is an indication of reduced synthesis or output from the mucus producing cells, a view supported by the finding that the numbers of goblet cells were similar in treated and control rats. One candidate molecule for this effect is histamine, which has been shown to influence mucus production ${ }^{16}$ and is known to be present in normal rat bile (Jackson and Storrier, unpublished observation).

The granular and vacuolated cells which predominate in mucus eluates carry the same surface markers (for example, asialo-GM1) and react similarly to specific cytochemical stains as cells with the characteristic morphology of epithelial cells. They are believed to be moribund forms of surface enterocytes which enter the mucus blanket after extrusion from the epithelial surface ${ }^{17}$ and have been grouped with epithelial cells in Table II. The numbers of these cells recoverable from duodenal mucus is greatly reduced in animals deprived of bile through cannulation of the bile duct. Possession of some, if not all, epithelial cell membrane characteristics suggests that these mucus associated cells may retain the ability to participate in bacterial adhesion reactions. Indeed, unpublished studies with Vibrio cholerae in experimental intestinal infections clearly show that many of the organisms are firmly attached to mucus associated cells. As this is probably true for other gut associated pathogens which require attachment to the intestinal epithelium as part of their pathogenic process, ${ }^{18}$ gross reductions in the number of mucus associated enterocytes could increase the ease with which pathogens penetrate the mucus to reach their epithelial target cells. Greater susceptibility to infection might therefore be anticipated in individuals lacking regular bile flow into the duodenum. It is known that epidermal growth factor (EGF) ${ }^{19}$ is a constituitive molecule of bile; it is known to act in the lumen ${ }^{20}$ and is therefore a prime candidate for homeostatic regulation of epithelial cell turnover. Its absence through prevention of bile flow to the lumen could therefore account for the observed significant decrease in epithelial cells present in the duodenal mucus.

A significant role in innate resistance has been assigned to the resident bacterial flora of the gut provided they are maintained within their natural ecological niches and that the balance between species is undisturbed. The continual interplay between host and parasite must serve the purposes of both. Earlier studies in our laboratory 2122 demonstrated the presence of antibodies (particularly IgA) against intestinal bacteria in rat bile and found, in particular, that the presence of coliforms was a major determinant in inducing normal levels of circulating and intestinal immunoglobulins. The present studies have shown that prevention of bile can cause subtle changes in the bacterial composition of caecal contents in most animals so far examined. Also, enhancement of the numbers of coliforms and their more obvious presence in the small intestine lead to the suggestion that factors present in bile contribute to the normal distribution of these bacteria. These observations may be relevant to the well known increased incidence of Gram negative sepsis in hepatobiliary disorders. Related to this is the recent finding that a seven day absence of normal bile flow in rats leads to translocation of bacteria (particularly coliforms) into mesenteric lymph nodes. ${ }^{23}$ The likely overgrowth of intestinal bacteria in this condition, coupled with a decreased level of natural antibody or other as yet undetermined factor(s) may be important features in facilitating invasion.

In summary, we propose that bile contributes to the control of homeostatic processes of both host and parasite in the gastrointestinal tract and that disturbance of its natural flow is likely to put the host at risk from invasion by its resident bacteria. Of current concern is how the changes observed in this study might influence specific phases of an infection by exogenous pathogens.

This work was supported by a grant from the National Health and Medical Research Council of Australia.

1 McGhee JR, Mestecky J. In defence of mucosal surfaces. Development of novel vaccines for IgA responses protective at the portals of entry of microbial pathogens. Infect Dis Clin North Am 1990; 4: 315-41.

2 Keclik M, Wolf RH, Felsenfeld O, Smetana HF Immunoglobulin and antibody in gall bladder bile. $A m \mathcal{F}$ Gastroenterol 1970; 54: 19-29.

3 Jackson GDF, Lemaitre-Coelho I, Vaerman JP, Bazin $\mathrm{H}_{\text {, }}$ Beckers A. Rapid disappearance from serum of intravenously injected rat myeloma IgA and its detection in venously injected rat myeloma IgA

4 Jackson GDF, Hansen PGC, Underdown BJ. Further evidence that hepatic sources confer biliary antibody in the rat. Immunology 1992; 76: 397-401.

5 Loftness TJ, Erlandsen SL, Wilson ID, Meyer EA. Occurrence of specific secretory immunoglobulin A in bile after inoculation of Giardia lamblia trophozoites into rat duodenum. Gastroenterology 1984; 87: 1022-9.

6 Pierre P, Langendries A, Vaerman JP. Cholera toxin neutralization: a comparison of purified IgG and biliary

secretory IgA antibodies. Immunol Lett 1988; 18: 51-6. Quesne LP. Gallstone disease presenting as septicaemic Quesne LP. Gallstone disease pre

8 Huang T, Bass JA, William RD. The significance of biliary pressure in cholangitis. Arch Surg 1969; 98: 629-32.

9 Lambert $R$. Surgery of the digestive system of the rat. Springfield, Ill: Thomas, 1965.

10 Keress S, Allen A, Garner A. A simple method for measuring thickness of the mucus gel layer adherent to rat, frog and human gastric mucosa: influence of feeding prostaglandin, N-acetylcysteine and other agents. Clin Sci 1982; 63: 187-95.

11 Altmann GG, Leblond CP. Factors influencing villus size in the small intestine of adult rats as revealed by transposition of intestinal segments. Am $\mathcal{f}$ Anat 1970; 127: 15-36.

2 Schaedler RW, Dubos R, Costello R. The development of the bacterial flora in the gastrointestinal tract of mice. thexp Med 1965; 122: 59-66.

13 Phillips $M$, Lee A, Leach WD. The mucosa-associated microflora of the rat intestine: a study of normal distribumicrolora of the rat intestine: a study of nosmal distribution and magnesium sulphate induced

14 Cooper GN, Narendranathan R. Antibacterial immunity to Vibrio cholerae in rats. $₹$ Med Microbiol 1986; 22: 133-41. 
15 Lee A. Neglected niches: The microbial ecology of the gastrointestinal tract. Advances in Microbial Ecology 1985; 8: $115-62$.

16 Scheiman JM, Kraus ER, Boland CR. Regulation of canine gastric mucin synthesis and phospholipid secretion by acid secretagogues. Gastroenterology 1992; 103:

17 Kalambaheti R. Influence of bile on parameters of innate immunity in the rat gastrointestinal tract. University of New South Wales, Sydney, 1991. (MSc dissertation.)

18 Robins-Browne RM. Traditional enteropathogenic Escherichia coli of infantile diarrhea. Rev Infect Dis 1987, 9: $28-53$.

19 Tuomela T, Vunikka L, Perheentupa J. Effects of estradiol and progesterone on epidermal growth factor concentra- tion in plasma, bile, urine, submandibular gland and kidney of the mouse. Horm Res 1989; 31: 143-7.

20 Konturek SJ, Dembinski A, Warzencha Z, Brozozowski T, Gregory $\mathrm{H}$. Role of epidermal growth factor in healing of chronic gastroduodenal ulcers in rats. Gastroenterology

21 Jackson GDF, Hansen PGC, Manning RJ. The nature and sources of natural biliary immunoglobulins. Protides of the biological fluids 1989; 36: 215-22.

22 Manning RJ, Walker PG, Carter L, Barrington PJ, Jackson GDF. Studies on the origin of biliary immunoglobulins in rats. Gastroenterology 1984; 87: 173-9.

23 Slocum MM, Sitting KM, Specian RD, Deitch EA Absence of intestinal bile promotes bacterial translocation. Am Surg 1992; 58: 305-10. 